\title{
Sanrılı Bozukluk ve Obsesif Kompulsif Bozukluk Hastalarında Üstbiliş İşlevlerinin Değerlendirilmesi
}

\section{Evaluation of Metacognitive Functions and Clinical Characteristics of the Patients Diagnosed with Obsessive Compulsive Disorder and Delusional Disorder}

\author{
Neslihan Çağlar ${ }^{1}$, Filiz Özsoy², Osman Mermi ${ }^{5}$ \\ 1 Karadeniz Ereğli Devlet Hastanesi Ruh Sağlığı ve Hastalıkları Kliniği, Ereğli/Zonguldak \\ 2 Tokat Ruh Sağlığı ve Hastalıkları Hastanesi, Tokat \\ 3 Fırat Üniversitesi Tıp Fakültesi Ruh Sağlığı ve Hastalıkları AD., Elazığ
}

ÖZET

Çalışmamızda; Obsesif Kompulsif Bozukluk (OKB) ve Sanrılı Bozukluk (SB) tanısı alan hastaların üstbiliş işlevlerinin ve klinik özelliklerinin kontrol grubuyla karşılaştırılarak değerlendirilmesi amaçlanmıştır

Çalışmaya Fırat Üniversitesi Hastanesi Ruh Sağlığı ve Hastalıkları Polikliniğine başvuran yatarak ya da ayaktan tedavi gören ve çalışma ölçütlerine uyan, OKB tanılı 50 hasta, SB tanılı 40 hasta ile hasta gruplarıyla yaş ve cinsiyet açısından eşleştirilmiş 50 sağlıklı kontrol alınmıştır. Hasta ve kontrol grubuna DSM-IV Eksen-ı Bozuklukları için Yapılandırımış Klinik Görüşme Ölçeği (SCID-I), Sosyodemografik ve Klinik Veri Formu, Üstbiliş Ölçeği-30 (ÜBÖ), OKB hasta grubuna ek olarak YaleBrown Obsesyon Kompulsiyon Ölçeği (Y-BOKÖ) ile Obsesif İnanışlar Ölçeği 44 (OiÖ-44), SB hastalarına ise Kısa Psikiyatrik Değerlendirme Ölçeği (KPDÖ) ile Beck Bilişsel İçgörü Ölçeği (BBiÖ) uygulanmıştır

Sonuç olarak; OKB ve SB hastalarının, üstbiliş toplam puanları kontrol grubuna göre yüksekti fakat istatistiksel olarak anlamlı sonuçlar sadece OKB hastalarında saptandı. OKB hastalarında; üstbiliş kontrol edilmezlik tehlike ile kontrol intiyacı alt boyutları, SB hastalarında ise; bilişsel güven alt boyutu kontrol grubuna kıyasla istatistiksel olarak anlamlı bulunmuştur. Ayrıca OKB hastalarında; Y-BOKÖ'nin kompulsiyonları değerlendiren alt boyutu ile kontrol intiyacı, OiÖ44'ün mükemmeliyetçilik/kesinlik ile kontrol edilmezlik tehlike alt boyutlar arasında, SB hastalarında ise; BBiö'nin kendini ifade etme ile bilişsel güven ve kendinden eminlik ile olumlu inanç alt boyutları arasında pozitif korelasyon saptanmıştır

Araştırmamızın sonuçları; OKB ve SB hasta grupları ile kontrol grubunun ÜBÖ parametreleri açısından farklııklar gösterdiğini ortaya koymuştur. Bu farklııklar ile OKB ve SB hastalıklarının nedensel ilişkisini saptamaya yönelik daha fazla sayıda çalışmaya gereksinim vardır

Anahtar kelimeler: Obsesif Kompulsif Bozukluk, Sanrılı Bozukluk, üstbiliş.
ABSTRACT

Our study aims to evaluate metacognitive functions and clinical characteristics of the patients diagnosed with Obsessive Compulsive Disorder $(O C D)$ and Delusional Disorder (SB) in comparison with the control group .

Patients, complying with the inclusion criteria, were chosen from inpatients and outpatients admitted to Firat University Hospital, Mental Health and IIIness Clinic. 50 patients with Obsessive Compulsive Disorder (OCD) and 40 patients with Delusional Disorder (DD) and 50 healthy controls who were matched with patient groups in terms of age and gender were included into study.

Structured Clinical Interview Scale for DSM-IV Axis I Disorders (SCID-I), sociodemographical and clinical interview form, metacognition assessment scale 30 (MAS), for OCD patient group additionally YaleBrown Obsessions and Compulsions Inventory (Y-BOCS) and Obsessive Beliefs Questionnaire-44 (OBQ44), for DD patients the Brief Psychiatric Rating Scale (BPRS) and Beck Cognitive Insight Scale (BCIS) were administered to patient and control groups.

As a result, although metacognition total scores of OCD and DD patient were higher than control group, statistically significant results were determined merely in OCD patients. In OCD patients metacognition uncontrollability and danger together with control need sub dimensions, in DD patients cognitive confidence sub dimension were statistically significant in comparison to control group. Moreover, in OCD patients a positive correlation between Y-BOCS's sub dimension evaluating compulsions and control need, between OBQ-44's sub dimensions perfectionism/ precision uncontrollability danger; in DD patients a positive correlation between BCIS's self-expression and cognitive confidence, selfassurance and positive belief sub dimensions were detected.

Results of our study put forward that $O C D$ and DD patient groups and control group present differences in terms of MAS parameters. More and more researches need to be carried out in order to determine casual relation between these differences and OCD and DD illnesses.

Key Words: Obsessive compulsive disorder, delusional disorder, metacognition, metacognition assessment scale 


\section{Giriş}

Sanrılı (paranoid) bozukluk (SB), gerçek yaşamla ilişkili olabilecek, tuhaf kaçmayan sistemli sanrıların olduğu, nispeten az görülen bir psiko- tik bozukluktur. Sanrılar dışında başka bir düşünce bozukluğu olmaz ve işlevsellik sanrısal alan dışında genellikle bozulmaz (1).

Obsesif kompulsif bozukluk (OKB), anksiyete bozuklukları içinde değerlendirilen ve obsesyon ve kompulsiyonlarla karakterize bir rahatsızlıktır. Obsesyon, kişiye sıkıntı veren, rahatsız edici, giri- ci ve yineleyici dürtü, düşünce ya da düşlemlerdir. Kompulsiyon ise, bir obsesyona tepki olarak ya da belli katı kurallara göre yapılan mental ya da motor eylemlerdir (1).

Üstbiliş (metacognition), bilişleri kontrol edip düzenleyen üst düzey bilişsel yapı ve süreçler olarak tanımlanabilir. Ayrıca, kişinin kendi zihnindeki olay ve işlevlerin farkında olmasını, zihin olaylarını ve işlevlerini amaçlı yönlendirebilme- sini içeren bir üst sistemdir (2). İnsanın bilişsel süreçlerinin işlevsel ve uyuma yönelik çalışmasında büyük rolü olan üstbiliş sisteminde meydana gelebilecek herhangi bir sapmanın, pek çok psikopatolojinin gelişmesi ve sürmesinde önemli olacağı düşünülmektedir (3). Buna göre, psikiyatrik rahatsızlıklardaki bazı işlevsel olmayan düşünce ve başa çıkma tarzlarına üstbilişsel işlevler yol açmaktadır. Yani, kişiler olayları değerlendirmelerini etkileyen işlevsel olmayan bilişleri hakkında bir takım olumlu ve olumsuz inançlara (üstbilişlere) sahiptirler. Bu tarzdaki üstbilişler kişinin uyuma yönelik olmayan tepki tarzları geliştirmelerine yol açmaktadır (4).

Sanrılı bozukluk ve OKB hastalarında üstbiliş ölçeği (ÜBÖ) kullanılarak yapılan çalışmalar sınırlı sayıdadır. Morrison ve Wells'inüstbiliş ölçeği kullanarak yaptıkları çalışmada, işitsel varsanıları olan hastalarda üstbiliş skorlarını perseküsyon sanrıları ve Panik bozukluğu (PB) olan hastalar ve kontrol grubuna kıyasla anlamlı derecede yüksek bulmuşlardır. Aynı çalışmada yine PB hastaları ve perseküsyon sanrıları olan psikotik hastalarda ÜBÖ skorları kontrol grubundan daha yüksek bulunmuştur (5). Yine Laroi ve Van der Lindenvarsanı ve sanrı yatkınlığı olanlarda ÜBÖ skorlarını herhangi bir yatkınlığı olmayan kişilere göre daha yüksek bulmuşlardır (6). Exner ve ark.'nın (7), OKB tanılı hastalardaki hafıza kusurlarının, bilişsel modelle izah edilebileceği düşüncesinden yola çıkarak yaptıklarıçalışmalarında; üst biliş puanlarının sağlıklı kontrol grubuyla kıyaslandığında daha yüksek olduğu bulunmuştur .

Bu çalışmada; SB ve OKB hastalarında üstbiliş- sel işlevlerin sağlıklı kontrol grubuyla farklılıkları ile hastalıkların ortaya çıkışı ve seyrini ne derece etkilediğini incelenmesi amaçlanmıştır.

\section{GEREÇ VE YÖNTEM}

\subsection{Verilerin toplanması}

Çalışmaya Fırat Üniversitesi Hastanesi Ruh Sağlığı ve Hastalıkları Polikliniğine 2012 yılı Haziran ayı ve 2013 yılı Haziran ayları arasındaki bir yıllık süreçte başvuran, yatarak ya da ayaktan tedavi gören ve çalışma ölçütlerine uyan, OKB tanılı 50 hasta, SB tanılı 40 hasta ile hasta gruplarıla yaş, cinsiyet açısından eşleştirilmiş 50 sağlıklı kontrol alınmıştır.

Hastalar için çalışmaya dahil edilme kriterleri: DSM-IV (AmericanPsychiatricAssociation 1994)'e göre, SB ve OKB tanısı konması, 18-65 yaşları arası olması, başka bir eksen I bozukluğunun eşlik etmemesi, okur-yazar olması ve yazılı bilgilendirilmiş gönüllü olur formunu imzalamış olmasıdır.

Hastalar için çalışmadan dışlama kriterleri: Geçmiş veya şimdiki öyküsünde psikoaktif madde kötüye kullanımı olması, 18 yaş altı, 65 yaş üstü olması, mentalretardasyon olması, beyin fonksiyonlarını etkileyebilecek düzeyde herhangi bir nörolojik veya sistemik hastalığının olmasıdır.

Kontrol grubu ise hasta grupları ile yaş ve cinsiyet açısından eşleştirilmiş, geçmiş veya şimdiki öyküsünde psikiyatrik bir hastalık tablosu veya mentalretardasyonu, psikoaktif madde kötüye kullanımı ve beyin fonksiyonlarını etkileyebilecek düzeyde herhangi bir nörolojik veya sistemik hastalığı olmayan kişiler arasından seçildi.

Çalışmaya alınan tüm hastalar ve sağlıklı kontrol grubuna, çalışmanın amacı ve yöntemi hakkında sözel ve yazılı bilgi verildikten sonra yazılı onamları alınmıştır. Bu çalışma için Fırat Üniversitesi Tıp Fakültesi Etik Kurulu'ndan onay alınmıştır. 


\section{Prosedür}

Çalışma hastalarının ayrıntılı anamnezleri alınarak, tedavinin başlangıcında DSM-IV Eksen-I Bozuklukları için Yapılandırılmış Klinik Görüşme Ölçeği (SCID-I) ile tüm olgulara klinik deneyim ve taranan kaynaklardan elde edilen bilgilere uygun olarak ve çalışmanın amaçları göz önünde bulundurularak tarafımızca hazırlanmış yaş, cinsiyet, medeni durum, eğitim durumu gibi sosyodemografik bilgileri ve hastalık süresi, atak sayısı, hastalık başlangıç yaşı gibi klinik verileri içeren yarı yapılandırılmış Sosyodemografik ve Klinik Veri Formu uygulanmıştır.

OKB ve SB tanısı konan hasta gruplarına ilk görüşme sırasında hasta onam formları açıklanıp imzalı onayları alınmıştır. OKB tanısı konulan hastaların obsesyon ve kompulsiyonlarını değerlendirmek için Yale-Brown Obsesyon Kompulsiyon Ölçeği (Y-BOKÖ), hastaların obsesyonlarının katılık düzeyini belirlemek amacıyla Obsesif İnanışlar Ölçeği 44 (OiÖ-44) uygulanmıştır. SB hastalarında hastalığın şiddetini değerlendirmek için Kısa Psikiyatrik Değerlendirme Ölçeği (KPDÖ), içgörü düzeyinin değerlendirilmesi için Beck Bilişsel İçgörü Ölçeği (BBï) uygulanmıştır. Tüm hastaların bilişsel işlevlerini değerlendirmek için Üst-Biliş- Ölçeği-30 (ÜBÖ-30) kullanılmıştır. Çalışma ile ilgili tüm görüşmeler tutarlılık olması açısından aynı kişi tarafından yapılmıştır.

\subsection{Kullanılan ölçekler 2.2.1. DSM-IV Eksen I Bozuklukları İçin Yapılandırılmış Klinik Görüşme (SCID-I) Ölçeği}

Diagnosticand Statistical Manual of MentalDisorders-IV Eksen I tanılarının konulması için geliştirilmiş, yarı yapılandırılmış bir klinik görüşme ölçeğidir. Türkçe uyarlama ve güvenirlik çalışması Çorapçıoğlu ve Aydemir (8) tarafından yapılmıştır.

\subsubsection{Yale-Brown Obsesyon Kompulsiyon Ölçeği (Y-BOKÖ)}

Obsesif kompulsif bozukluğu olan hastalarda belirtilerin niteliğinin belirlenerek semptom şiddetinin ölçülmesi ve tedavi sonrası değişimin de ğerlendirilmesinde kullanılan önemli bir araçtır. Ölçek, Uluğ ve Savaşır tarafından Türkçe'ye çevrilmiş, Karamustafalıoğlu ve ark. (9) tarafından 1993 yılında geçerlik ve güvenilirliği yapılmıştır. Toplam 19 maddeden oluşan ölçekte değerlendirmeye ilk 10 maddenin puanları dahil edilmektedir. ilk 5 madde obsesyonları, 6-10. maddeler kompulsiyonları değerlendirir.. Puanlamayı, görüşmeyi yapan klinisyen yapar ve toplam puan 0-40 arasında değişir. Ölçekten elde edilen puanların semptom şiddetine göre derecelendirilmesi; 0-7 subklinik, 815 hafif, 16-23 orta, 24-31 şiddetli, 32-40 ise çok şiddetli şeklindedir.

\subsubsection{Obsesif İnanışlar Ölçeği-44 (Oiö-44)}

Obsesesif inanışları değerlendirmek üzere hazırlanan Obsesif İnanışlar Ölçeği (OiÖ-44); 44 maddeden oluşan ve yedili derecelendirme (1= kesinlikle katılmıyorum, $2=$ katılmıyorum ve $7=$ kesinlikle katılıyorum gibi) ile hazırlanan ifadelere katılımcının ne kadar katıldığını belirtmeleri istenen bir öz-bildirim ölçeğidir. Ölçek üç faktör yapısına sahiptir: sorumluluk/tehdit öngörüsü, mükemmeliyetçilik/kesinlik, düşüncelerin ve kontrolün önemsenmesi. Türkçe uyarlaması Boysan ve arkadaşları (10) tarafından yapılmıştır.

\subsubsection{Kısa Psikiyatrik Değerlendirme Ölçeği (KPDÖ)}

Şizofreni ve diğer psikotik bozukluklarda tablonun şiddetini değerlendirmek için geliştirilen ölçek 18 maddeden oluşur ve semptomlar "yok=0 puan ila aşırı derecede şiddetli=6 puan" arasında puanlandırılır. Anksiyete, depresyon, düşünce bozukluğu, saldırganlık ve ajitasyonla ilgili de bilgi verir. Ölçeğin Türkçe uyarlaması Soykan (11) tarafından yapılmıştır.

\subsubsection{Beck Bilişsel i̇çgörü Ölçeği (BBiö)}

İçgörünün değerlendirilmesi için hazırlanmış ölçek, 15 maddeden oluşur ve bir özbildirim ölçeğidir. Dörtlü derecelendirme $(0=$ hiç katılmıyorum, 1=çok az katılıyorum, 2=epeyce katılıyorum, $3=$ tamamen katılıyorum) ile hazırlanan ifadelere katıımcıların ne kadar katıldıklarını belirtmeleri istenir. Hastanın yüksek puan alması yüksek içgörü düzeyini gösterir. Türkçe uyarlaması Aslan ve arkadaşları (12) tarafından yapılmıştır. 


\subsection{6. Üst-Biliş-Ölçeği-30 (ÜBÖ)}

Cartwright-Hatton ve Wells tarafından geliştirilen ve psikometrik çalışmaları yapılan ÜBÖ, kavramsal olarak birbirinden farklı, fakat birbiriy- le ilişki içinde olan beş faktörden oluşmaktadır. Bu beş faktör, (1) olumlu inançlar, (2) bilişsel güven, (3) kontrol edilemezlik ve tehlike, (4) bilişsel farkındalık ve (5) kontrol ihtiyacı şeklindedir. Tüm faktörler, olumlu ve olumsuz üstbilişsel inançlar (yapılar) ile üstbilişsel süreçler (seçici dikkat, içsel bilişsel süreçlerin gözlenmesi) şeklinde güvenirliği .72 ile .89 arasında değiştiği bulunmuştur. ÜBÖ kullanılarak yapılan çalışmalar, düşünceler hakkındaki olumsuz inançların yaygın kaygı bozukluğu hastalarını diğer kaygı bozukluklarından ayırt ettiğini göstermektedir (13). Türkçe geçerli- lik-güvenilirlik çalışması Tosun ve Irak (14) tarafından yapılmıştır.

\section{3. İstatistiksel Değerlendirme}

Çalışmada elde edilen verilerin istatiksel analizleri için, SPSS (Statistical PackageforSocialSciences) for Windows 15 programı kullanılmıştır. İstatistiksel değerlendirmelerde; değişkenler arasındaki ilişkilerin analizi ile hasta ve kontrol gruplarının sosyodemografik özellikleri için ki-kare testi, kullanılan ölçekler yönünden hasta ve kontrol gruplarından elde edilen puanlar arasındaki farkların değerlendirilmesi için t-testi (parametric test) kulanılmıştır. Değişkenler arası ilişkilerin incelenmesi için Pearson Korelasyon analizlerinden yararlanılmıştır.

\section{BULGULAR}

\subsection{Hasta ve kontrol grubunun sosyodemog-} rafik özellikleri

Çalışmaya alınan grupların yaşlarının ortalaması; OKB için $32.78 \pm 11.77$, SB için $33.88 \pm 11.77$ ve kontrol grubunun ise $32.38 \pm 10.65$ idi. Çalışmaya alınan OKB hasta grubunun 28'i kadın (\%41.8), 22'si erkek (\%66.7), SB hastalarının 13'ü kadın (\%32.5), 26 'sı erkek (\%67.5), kontrol grubunun ise 26 'sı kadın (\%27.4), 24'ü erkek (\%43.6) idi. OKB ve SB hasta grupları ile sağlıklı kontrol grubu arasında sosyodemografik özellikler yönünden istatistiksel olarak anlamlı bir farklılık saptanmamıştır ( $p>0.05)$. (Tablo 1).

\begin{tabular}{|c|c|c|c|}
\hline & OKB $(n=50)$ & SB $(n=40)$ & Kontrol $(n=50)$ \\
\hline Yaş & $32.78 \pm 11.77$ & $33.88 \pm 11.77$ & $32.38 \pm 10.65$ \\
\hline Cins (E/K) & $22 / 28$ & $26 / 13$ & $24 / 26$ \\
\hline $\begin{array}{l}\text { Eğitim Durumu } \\
\text { Okuryazar-ilkokul } \\
\text { Ortaokul } \\
\text { Lise } \\
\text { Üniversite }\end{array}$ & $\begin{array}{c}13 \\
\\
4 \\
18 \\
15\end{array}$ & $\begin{array}{l}18 \\
6 \\
8 \\
8\end{array}$ & $\begin{array}{c}8 \\
\\
7 \\
20 \\
15\end{array}$ \\
\hline $\begin{array}{l}\text { Medeni Durum } \\
\text { Evli } \\
\text { Bekar } \\
\text { Boşanmış } \\
\text { Dul }\end{array}$ & $\begin{array}{l}26 \\
24 \\
-\end{array}$ & $\begin{array}{c}24 \\
12 \\
1 \\
3\end{array}$ & $\begin{array}{l}36 \\
14 \\
- \\
-\end{array}$ \\
\hline $\begin{array}{l}\text { Yaşadığı Yer } \\
\text { Köy } \\
\text { Kasaba } \\
\text { Şehir }\end{array}$ & $\begin{array}{c}3 \\
1 \\
46\end{array}$ & $\begin{array}{c}4 \\
3 \\
33\end{array}$ & $\begin{array}{c}1 \\
49\end{array}$ \\
\hline Meslek & & & \\
\hline Ev hanımı & 20 & 12 & 7 \\
\hline Öğrenci & 13 & 2 & 5 \\
\hline Memur & 6 & 7 & 13 \\
\hline işçi & 1 & 5 & 21 \\
\hline Özel sektör & 1 & 1 & 3 \\
\hline işsiz & 5 & 3 & - \\
\hline Emekli & 2 & 8 & 1 \\
\hline Diğer & 2 & 2 & - \\
\hline
\end{tabular}

* $p>0.05$, Tüm değişkenlerde hasta ve kontrol gruplarının karşılaştııılması

\subsection{Hasta ve kontrol grubunun ölçek puanları}

Hasta ve kontrol grubuna uygulanan ÜBÖ sonuçları:

Total puanlar; OKB hasta grubunun total puanlarının ortalaması $85.36 \pm 9.64$, SB hasta grubunun $73.05 \pm 15.85$ ve kontrol grubunun ise $71.22 \pm 14.67$ idi. OKB hastalarının total puan sonuçları sağlıklı kontrollere kıyasla istatistiksel olarak anlamlı bulunmuştur $(p<0.05)$. Hasta grupları kendi aralarında kıyaslandığında da sonuçlar anlamlı bulunmuştur (SB ve OKB hastaları kıyaslandığında $p=0.000, O K B$ hastaları kontrollerle kıyaslandığında $p=0.005$, SB hastaları kontrollerle kıyaslanınca $\mathrm{p}=0.285$ olarak saptanmıştır).

Üstbiliş ölçeği olumlu inanç alt boyutu; kontrol grubunun bu alt boyuta ait puanlarının ortalaması $14.26 \pm 4.33$, OKB hastalarında 15.26 \pm 3.47 , SB hastalarında ise $13.15 \pm 4.05$ olarak hesaplanmıştır. Bu alt boyut açısından gruplar arasında 
anlamlı farklılık saptanmamıştır(Kontrol grubu OKB hastaları ile kıyaslandığında $p=0.075$, SB hastaları ile kıyaslandığında $p=0.677$ olarak bulunmuştur. Hasta grupları kendi aralarında kıyaslandığında ise $p=0.186$ olarak saptanmıştır). Bilişsel güven alt boyutu; kontrol grubunun bilişsel güven puanlarının ortalaması $12.52 \pm 3.85$, OKB hastalarının $16.6 \pm 4.53$ ve SB hastalarının $12.42 \pm 5.66$ olarak hesaplanmıştır. OKB hastalarının kontrol grubuna kıyasla bu alt boyuta ait puanları istatistiksel olarak anlamlı bulunmuştur, SB hastalarının ise sonuçları istatistiksel olarak anlamlı olmadığı saptanmıştır. Hasta grupları kendi aralarında kıyaslandığında da sonuçlar anlamlı bulunmuştur (Kontrollerle SB hastaları kıyaslandığında $p=0.002$, OKB hastaları kıyaslandığında $p=0.804$ ve hasta grupları kendi aralarında kıyaslandığında ise $\mathrm{p}=0.019$ olarak saptanmıştır). Kontrol edilmezlik ve tehlike alt boyutu; kontrol grubunun bu alt boyuta ait puanlarının ortalaması $17.24 \pm 4.56$, OKB hastalarının $20.28 \pm 3.17$ ve SB hastalarının ise $18.35 \pm 5.45$ olarak hesaplanmıştır. Kontrol grubuna kıyasla OKB hastalarında bu alt boyut istatistiksel olarak anlamlı bulunmuştur, SB hastalarında anlamlı bulunmamıştır. Hasta grupları kendi aralarında kıyaslandığında da sonuçlar anlamlı bulunmuştur (Kontrol grubu ile OKB hastaları kıyaslandığında $p=0.011$, SB hastaları kıyaslandığında $p=0.186$ ve hasta grupları kendi aralarında kıyaslandığında $p=0.000$ olarak saptanmıştır). Bilişsel farkındalık alt boyutu;kontrol grubunun bu alt boyuta ait puanlarının ortalaması $16.20 \pm 4.28$, OKB hastalarının 17.56 \pm 3.48 , SB hastalarının ise $16.32 \pm 4.16$ olarak hesaplanmıştır. Gruplar arasında istatistiksel olarak anlamlı farklılık saptanmamıştır (OKB hastaları ve kontroller kıyaslandığında $p=0.103$, SB hastaları kontrollerle kıyaslandığında $p=0.755$ ve hasta grupları kendi aralarında kıyaslandığında $p=0.225$ saptanmıştır). Kontrol ihtiyacı alt boyutu; kontrol grubunun bu alt boyuta ait puanlarının ortalaması $11.54 \pm 3.48$, OKB hastalarının ise $15.36 \pm 2.03$, SB hastalarının ise $12.55 \pm 2.96$ olarak hesaplanmıştır. OKB hastalarının bu alt boyuta ait sonuçları hem kontrollere hem de SB hastalarına kıyasla istatistiksel olarak anlamlıydı. SB hastalarında ise sonuçlar istatistiksel olarak anlamlı olmadığı görülmüştür (Kontrollerle OKB hastaları kıyaslandığında $\quad \mathrm{p}=0.001, \quad \mathrm{SB} \quad$ hastaları kıyaslandığında $p=0.378$ ve hasta grupları kendi aralarında kıyaslandığında ise $p=0.006$ olarak saptanmıştır). Hasta ve kontrol grubunun ÜBÖ sonuçlarına ait veriler Tablo 2 ve 3'de verilmiştir.

\subsection{Hasta ve kontrol grubunun korelasyon analizleri}

Hasta gruplarına uygulanan ve hastalıkların şiddetini değerlendirmemizi sağlayan ölçeklerle üstbiliş arasındaki ilişki incelendiğinde:

Obsesif kompulsif bozukluk hastaları için; YBOKÖ'nin toplam puanları ve obsesyonları değerlendiren soruları ile ÜBÖ hem total puanları hem de alt boyutları arasında istatistiksel hiçbir anlamlılık tespit edilmemiştir ( $p>0.05)$.

\begin{tabular}{|c|c|c|c|c|c|c|}
\hline \multirow[t]{2}{*}{ ÜBÖ } & \multirow{2}{*}{$\begin{array}{l}\text { Kontrol } \\
(n: 50)\end{array}$} & \multirow{2}{*}{$\begin{array}{c}\text { SB } \\
(n: 40)\end{array}$} & \multirow{2}{*}{$\begin{array}{c}\text { OKB } \\
(n: 50)\end{array}$} & \multirow{2}{*}{\begin{tabular}{ll|} 
Hasta & gruplarının \\
kıyaslanması &
\end{tabular}} & \multicolumn{2}{|c|}{ Istatistik } \\
\hline & & & & & $f$ & $\mathbf{P}$ \\
\hline Total puan & $71.22 \pm 14.67$ & $73.05 \pm 15.85$ & $85.36 \pm 9.64$ & OKB $>S B=$ kontrol & $15.903^{*}$ & 0.000 \\
\hline Olumlu inanç & $14.26 \pm 1.23$ & $13.15 \pm 4.05$ & $15.26 \pm 0.49$ & OKB=SB=kontrol & 4.156 & 0.080 \\
\hline Bilişsel güven & $12.52 \pm 1.09$ & $12.42 \pm 5.66$ & $16.6 \pm 0.64$ & SB>OKB=kontrol & $12.525^{*}$ & 0.000 \\
\hline Kontrol edilmezlik ve tehlike & $17.24 \pm 1.29$ & $18.35 \pm 5.45$ & $20.28 \pm 0.44$ & OKB $>S B=$ kontrol & $6.036^{*}$ & 0.003 \\
\hline Bilişsel farkındalık & $16.20 \pm 1.21$ & $16.32 \pm 4.16$ & $17.56 \pm 0.49$ & OKB=SB=kontrol & 1.738 & 0.180 \\
\hline Kontrol ihtiyacı & $11.54 \pm 0.98$ & $12.55 \pm 2.96$ & $15.36 \pm 0.28$ & OKB $>S B=$ kontrol & 23.314* & 0.000 \\
\hline
\end{tabular}




\begin{tabular}{|l|l|c|c|c|c|c|}
\hline \multicolumn{1}{|l|}{ Tablo B. Grupların ÜBÖ sonuçlarının istatistiksel olarak karşılaştırılması. } \\
\hline \\
\hline
\end{tabular}

${ }^{*} p<0.05,{ }^{*} p<0.01$

Y-BOKÖ'ninkompulsiyonları değerlendiren soruları ve ÜBÖ'nin sadece kontrol ihtiyacı alt boyutu arasında istatistiksel olarak anlamlılık saptanmıştır ( $p=0.037$ idi). Oiö-44'ün toplam puanları ve sorumluluk/tehlike beklentisi alt faktörü arasında ÜBÖ'nin hem toplam puanları hem de alt boyutları arasında istatistiksel herhangi bir anlamlılık saptanmamıştır $\quad(p>0.05)$ OiÖ-44 mükemmelliyetçilik/kesinlik faktörü ile ÜBÖ kontrol edilmezlik ve tehlike alt boyutu arasında ve Oiö-44 önem verme/düşünceleri kontrol etme faktörü ile de ÜBÖ bilişsel farkındalık arasında istatistiksel olarak anlamlı farklılık saptanmıştır(Mükemmelliyetçilik/kesinlik faktörü için $p=0.022$, önem verme/düşünceleri kontrol etme için $p=0.029$ olarak değerlendirilmiştir). ÜBÖ ile $Y$ BOKÖ ve Oї̈-44 arasındaki korelasyon sonuçlarına ait veriler Tablo 4 'te verilmiştir.

Sanrısal bozukluk hastaları için; BBiÖ'nin kendini ifade etme alt boyutu ÜBÖ'nin toplam skor ları ve bilişsel güven alt boyutu ile,BBiÖ'nin kendinden eminlik alt boyutu ise olumlu inanç ve ÜBÖ toplam skorlar ile istatistiksel olarak kore- le olduğu görülmüştür $(p<0.05)$. Kısa psikiyatrik değerlendirme ölçeği ile ÜBÖ'nin hem toplam puanları hem de alt boyutları arasında istatistiksel olarak anlamlı bir ilişki saptanmamıştır. ÜBÖ ile BBiÖ ve kısa psikiyatrik değerlendirme ölçeği korelasyon sonuçlarına ait veriler Tablo 5 'te verilmiştir.

\section{TARTIŞMA}

$O K B$ ve $S B$ hastalarında üstbiliş işlevlerinin değerlendirilmesini amaçladığımız çalışmamızda, $O K B$ ve $S B$ hastalarının üstbiliş toplam puanları kontrol grubuna göre yüksek olduğu saptanmıştır fakat istatistiksel olarak anlamlı sonuçlar sadece OKB hastalarında saptanmıştır. OKB hastalarında; üstbiliş kontrol edilmezlik tehlike ile kontrol ihtiyacı alt boyutları, SB hastalarında ise; bilişsel güven alt boyutu kontrol grubuna kıyas

\begin{tabular}{|c|c|c|c|c|c|c|c|c|}
\hline \multicolumn{3}{|l|}{ ÜBÖ } & \multirow{2}{*}{$\begin{array}{l}\begin{array}{l}\text { Toplam } \\
\text { puan }\end{array} \\
0.001 \\
\end{array}$} & \multirow{2}{*}{$\begin{array}{l}\begin{array}{l}\text { Olumlu } \\
\text { inanç }\end{array} \\
0.056\end{array}$} & \multirow{2}{*}{$\begin{array}{l}\begin{array}{l}\text { Bilişsel } \\
\text { güven }\end{array} \\
0.102 \\
\end{array}$} & \multirow{2}{*}{\begin{tabular}{|l|}
$\begin{array}{l}\text { Kontrol } \\
\text { edilmezlik ve } \\
\text { tehlike }\end{array}$ \\
-0104
\end{tabular}} & \multirow{2}{*}{$\begin{array}{c}\begin{array}{c}\text { Bilişsel } \\
\text { farkındalık }\end{array} \\
0.002\end{array}$} & \multirow{2}{*}{$\begin{array}{l}\text { Kontrol } \\
\text { ihtiyacı } \\
-0.157\end{array}$} \\
\hline \multirow{7}{*}{ ОКВ } & \multirow{3}{*}{ Y-ВОкÖ } & Obs & & & & & & \\
\hline & & Komp & -0.061 & 0.199 & -0.035 & -0.216 & 0.048 & $0.295^{*}$ \\
\hline & & Total puan & -0.033 & 0.141 & 0.033 & -0.175 & 0.028 & -0.247 \\
\hline & \multirow{4}{*}{ oíö-44 } & 1. faktör & -0.085 & 0.037 & -0.151 & -0.056 & 0.098 & 0.644 \\
\hline & & 2. faktör & 0.167 & -0.105 & 0.091 & $0.324^{*}$ & $0.308^{*}$ & 0.091 \\
\hline & & 3. faktör & 0.211 & 0.047 & 0.066 & 0.177 & 0.200 & -0.032 \\
\hline & & Total puan & 0.128 & -0.018 & -0.018 & 0.219 & 0.200 & -0.010 \\
\hline
\end{tabular}

1. faktör=Sorumluluk/tehlike beklentisi, 2 . faktör=Mükemmeliyetçilik/kesinlik, 3. faktör $=$ Önem verme/düşünceleri kontrol etme, ${ }^{*} \mathrm{P}<0.05$ 


\begin{tabular}{|c|c|c|c|c|c|c|c|}
\hline \multicolumn{8}{|c|}{ ÜBÖ } \\
\hline & & Total puan & $\begin{array}{l}\text { Olumlu } \\
\text { İnanç }\end{array}$ & $\begin{array}{l}\text { Bilişsel } \\
\text { güven }\end{array}$ & \begin{tabular}{|l|} 
Kontrol edilmezlik \\
ve tehlike
\end{tabular} & $\begin{array}{c}\text { Bilişsel } \\
\text { farkındalık }\end{array}$ & $\begin{array}{l}\text { Kontrol } \\
\text { intiyacı }\end{array}$ \\
\hline \multirow[t]{2}{*}{ 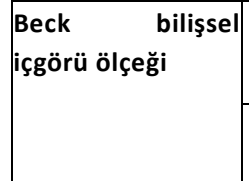 } & $\begin{array}{l}\text { Kendini ifade } \\
\text { etme }\end{array}$ & $0.397^{*}$ & 0.279 & $0.352 *$ & 0.254 & 0.257 & 0.165 \\
\hline & $\begin{array}{l}\text { Kendinden } \\
\text { eminlik }\end{array}$ & $0.371^{*}$ & $0.348^{*}$ & 0.136 & 0.252 & 0.282 & 0.263 \\
\hline \multicolumn{2}{|c|}{ Kısa psikiyatrik değerlendirme ölçeği } & 0.101 & 0.143 & 0.059 & 0.025 & -0.018 & 0.156 \\
\hline
\end{tabular}

$* \mathrm{P}<0.05$

la istatistiksel olarak anlamlı olarak saptanmıştır. Ayrıca OKB hastalarında; Y-BOKÖ'nin kompulsiyonları değerlendiren alt boyutu ile kontrol intiyacı, OiÖ-44'ün mükemmeliyetçilik/kesinlik ile kontrol edilmezlik tehlike alt boyutları arasında, SB hastalarında ise; BBiÖ'nin kendini ifade etme ile bilişsel güven ve kendinden eminlik ile olumlu inanç alt boyutları arasında pozitif korelasyon saptanmıştır.Araştırmamızın sonuçları; OKB ve SB hasta grupları ile kontrol grubunun ÜBÖ parametreleri açısından farklılıklar gösterdiğini ortaya koymuştur.Morrison ve Wells'in(5) PB hastaları ve psikotik hastaların üstbiliş sistemini değerlendirdikleri çalışmalarında; işitsel hallüsinasyonu olan hastalarda ÜBÖ skorlarını perseküsyon sanrıları, PB olan hastalar ve kontrol grubuna kıyasla anlamlı olarak yüksek bulmuşlardır. Aynı çalışmada PB hastaları ve perseküsyon san rıları olan psikotik hastalarda ÜBÖ skorları kontrol grubundan yüksek çıkmıştır. Çalışmamızda ise; OKB hastalarında ÜBÖ total skorları, kontrol edilmezlik tehlike ve kontrol ihtiyacı, SB hastalarında ise; bilişsel güven alt boyutu istatistiksel olarak anlamlı bulunmuştur.Laroi ve Van der Linden (6)varsanı ve sanrı yatkınlığı olan kişilerde üstbiliş ölçeği skorlarını herhangi bir yatkınlığı olmayan kişilere göre daha yüksek bulmuşlardır. Yine başka bir çalışmada da işitsel hallüsinasyo- nu ve perseküsyon sanrıları olan hastalarda ÜBÖ total skorları sağlıklı kontrollere göre anlamlı olarak yüksek bulunmuştur (5). Çalışmamızda ise her iki hastalık grubunda da ÜBÖ total skorları sağlıklı kontrollerden yüksek olmakla birlikte istatistiksel olarak anlamlı sonuçlar sadece OKB hastalarında saptanmıştır. Ayrıca SB hastalarının içgörülerini değerlendirmek amacıyla uygulanan BBï̈'nin her iki alt faktörüyle de total skorlar pozitif yönde korele olduğu gözlenmiştir.Üstbilişin bilişsel güven alt boyutu, SB hastalarında anlamlıydı ve BBï̈'nin kendini ifade etme alt boyutu ile de pozitif yönde korele olarak saptanmıştır. Bilişsel güven alt boyutunda kişilerin hafızalarına olan güvensizlikleri ya da yaşadıkları hafıza problemleri, unutkanlıkları değerlendirilmektedir. SB hastalarında bu alt boyutun anlamlılığı, hastaların hafızalarına olan güvensizlikleri ya da unutkanlık beraberinde şüphe duyma ile ilişkili olabileceğini düşündürmektedir. Ayrıca hastaların diğer insanların kendilerine karşı tutumlarını yanlış anlayıp anlamadıklarını, diğer insanların olağandışı yaşantılarınının nedenlerini kendi anladıklarından daha iyi anlamalarını ve sanrılarının varlığından emin olmayı değerlendiren BBiö kendini ifade etme boyutu ile de pozitif yönde korelasyon saptanmıştır. Bu da hastaların unutkanlıkları, hafıza problemleri arttıkça sanrılarından duydukları şüphelerinin de arttığını düşündürmektedir.

Hermans ve ark. (15) OKB hastalarının bilişsel güvenlerinin normal gruba oranla daha düşük olduğunu belirtmişlerdir.Bruin, Muris ve Rassin(16) klinik olmayan bir örneklemden aldıkları ölçümler sonucunda kişilerin kendi düşüncelerine dair farkındalıklarının ve girici düşüncelere dair olumsuz değerlendirmelerinin obsesif düşünceleri ve düşünceyi bastırma çaba 
sının da endişeyi yordadığına dair bulgular elde etmişlerdir.Cuchii ve ark. (17) OKB hastalarında kontrol edilmezlik tehlike ve kontrol ihtiyacı alt boyutlarını anlamlı olarak yüksek saptamıştır ve hastaların endişelenmek konusunda sağlıklı kontrollerden daha olumsuz inanışlarının olduğunu da vurgulamışlardır .Moritz ve ark. (18) OKB hastalarındaki kontrol edilmezlik tehlike alt boyutununun yüksekliğinin obsesyonların ciddiyeti ile ilişkili olduğunu bulmuşlardır.Sica ve ark. (19) OKB hastalarında obsesif-kompulsif semptomlar ve patolojik endişe ile üstbilişin kontrol edilmezlik tehlike alt boyutunun ve hastaların ritüelleri ile ise kontrol ihtiyacı alt boyutunun ilişkili olduğunu ortaya koymuşlardır.Myers ve ark.(20) OKB hastalarının metakognitif modelini ortaya koydukları çalışmalarında; hastaların üst- bilişsel çarpıtmalarının hastalığın ortaya çıkmasında ve devamında önemli rol oynadığını ortaya koymuşlardır .Grotte'nin (21) çalışmasında ise; obsesyonların sorumluluk ve mükemmeliyetçi- lik duygusu ile ilişkili olduğu ve OKB hastalarında üstbilişsel çarpıtmalar olduğu bildirilmiştir . Irak ve Tosun (14); Türkiye'den 850 üniversite öğrencisiyle yürüttükleri çalışmada üstbilişlerin, özellikle kontrol edilmezlik tehlike boyutuna dair üstbilişsel inançların, obsesif-kompulsif belirtiler ve sürekli kaygıyı birbirinden bağımsız olarak güçlü bir şekilde yordadığınıgöstermişlerdir .Corcoran ve Woody (22) de yine normal örneklemle çalıştıkları araştırmalarında, saldırganlık, cinsellik ve günahkarlığa dair, sosyal kabul görmeyecek düşünceleri katılımcıların değerlendirmesini istemişler ve düşüncelerin kendini kötü karakteri olan bir kişi olarak görme, zihinsel bir bozuklukla ilişkilendirme, ahlaksızlık gibi değerlendirmelerin obsesif-kompulsif belirtilerle ilişkili olduğuna dair sonuçlar elde etmişlerdir.Üstbilişin olumlu inanç alt boyutu; endişelenmenin kişinin kendisi için olumlu ya da kurtarıcı bir durum olup olmadığını sorgulamaktadır. Bizim sonuçlarımıza göre, hem OKB hem de SB hastalarında olumlu inanç alt boyutu istatistiksel olarak anlamlı değildi. Bu durum, her iki hastalıkta da hastaların endişelenmeyi kendileri için olumlu ya da kurtarıcı bir durum olarak görmediklerini düşündürmektedir. Ancak, SB hastalarına uygulanan BBiÖ'nin kendinden eminlik alt boyutu ve olum lu inanç alt boyutu arasında pozitif korelasyon saptandı.BBï̈'nin hastaların yaşantıları ile ilgili yorumlarının kesinliği gibi düşüncelerine olan güvenlerinin sorgulandığı kendinden eminlik alt boyutunun olumlu inanç ile olan korelasyonu hastaların sanrıları yoğunlaştıkça daha az endişe duydukları ya da endişelenmeyi olumlu olarak gördükleri veya rahatsız edici olarak görmedikleri şeklinde yorumlanmıştır. Nieto ve ark. (23) YAB ve OKB tanılı hastalarda; ÜBÖ olumlu inanç alt boyutunda sağlıklı kontrollere kıyasla istatistiksel olarak anlamlı farklılık saptamamışlardır. Benzer şekilde, Cuchii ve ark. (17) PB ve OKB hastalarında yaptıkları çalışmalarında, olumlu inanç alt boyutunu anlamlı olarak değerlendirmemişlerdir.Çalışmamızda kişilerin aklından geçenlerle uğraşmaları ve düşüncelerini sürekli gözden geçirip takip etmelerinin değerlendirildiği bilişsel farkındalık alt boyutu; hem SB hem de OKB hastalarında istatistiksel olarak anlamlı olmadığı saptanmıştır. Ancak OKB hastalarına uygulanan OiÖ-44'ün önem verme/düşünceleri kontrol etme alt boyutu ile pozitif yönde korelasyon saptanmıştır. Oï̈-44'ün önem verme/düşünceleri kontrol etme alt boyutunda sorgulanan, bir şeyi düşünmenin yapmakla eşdeğer olup olmaması ve kötü düşüncelere sahip olmanın düşünülen şeyi yapmakla eşdeğer olarak görülüp görülmediğidir. Çalışmamızda bu iki alt boyut arasında saptadığımız anlamlılık OKB hastalarının yaşadıkları kuşkular ve kontrol etme ihtiyacı duymaları ile ilişkili olabileceği düşünülmüştür. Safrancı ve ark.tarafından (24) üniversite öğrencilerinde yapılan çalışmada; üstbiliş bilişsel farkındalık alt boyutunun endişe duyma, sosyal kaçınma ile pozitif yönde ilişkili olduğunu bulmuştur. Başka bir çalışmada ise; obsesyonların ve bilişsel farkında- lığın sorumluluk ve mükemmeliyetçilik duygusu ile olan ilişkisi ortaya konulmuştur (21).Kontrol ihtiyacı alt boyutunda ise; kişilerin düşüncelerini sürekli kontrol etmeleri ve belli şeylerin düşünülmesinin kötülüğüne olan inançları sorgulanmaktadır. Çalışmamızda; SB hastalarında bu alt boyut istatistiksel olarak anlamlı değildi, OKB hastalarında ise anlamlı olarak yüksek olarak bulunmuştur. Ayrıca OKB hastalarına uygulanan ve hastaların semptomlarının şiddetini değerlendirmemize yardımcı olan Y-BOKÖ'nin kompulsi- 
yonları değerlendiren soruları ile pozitif yönde korelasyonsaptanmıştır. Bu sonuç da OKB hastalarının pek çok şeyi tekrar tekrar kontrol etmesi ya da yaşadıkları kuşkular ile ilişkili olabileceği şeklinde yorumlanmıştır. Cartwright-Hatton ve Wells'in ve Matthews ve ark.'nın $(4,25) O K B$ hastalarında yaptıkları farklı çalışmalarda da hastaların kontrol ihtiyacı alt boyutunu anlamlı olarak değerlendirmişlerdir.Gwilliam ve ark. (26) OKB hastalarında kontrol ihtiyacı alt boyutunu obsesyonların katılığı ile ilişkilendirmişlerdir. Başka bir çalışmada; OKB hastalarında kontrol edilmezlik tehlike ile kontrol ihtiyacı, YAB hastalarında olumlu inanç, depresif bozukluk hastalarında ise bilişsel güven alt boyutu anlamlı olarak değerlendirilmiştir (27). Garcia-Montes ve ark. (28)

\section{KAYNAKLAR}

1. Köroğlu E, Güleç C. Psikiyatri Temel Kitabı. 2. Baskı, Ankara: Hekimler Yayın Birliği, 2007: 343-351

2. Crick F. Şaşırtan Varsayım. Say S (Çeviren) s. 151, Ankara, тÜвітAK Yayınları, 2000.

3. Wells A, Cartwright-Hatton S. A short form of themetacognitionsquestionnaire: properties of the MCQ 30 . BehavResTher 2004; 42: 385-396.

4. Cartwright-Hatton S, Wells A. Beliefsaboutworryandintrusions: themetacognitionsquestionnaireanditscorre- lates. J AnxietyDisord 1997; 11: 279-296.

5. Morrison AP, Wells A. A comparison of metacognitions in patientswithhallucinations, delusions, panicdisorder, andnon-patientcontrols. BehavResTherapy 2003; 41: 251256.

6. Laroi F, Van der Linden M. Metacognition in pronenesstowardshallucinationsanddelusions. BehavResTherapy 2005; 43: 1425-1441.

7. ExnerC, Kohl A, Zaudig M, Langs G, Lincoln TM, Rief $\mathbf{W}$. Metacognitionandepisodicmemory in obsessive-compulsivedisorder. J AnxietyDisorders 2009; 23: 624-631.

8. Çorapçıoglu A, Aydemir Ö. DSM-IV Eksen I Bozuklukları (SCID-I) için Yapılandırılmış Klinik Görüşme-Klinik Versiyon. Ankara: Hekimler Birliği Yayınevi, 1999: 73-75.

9. Karamustafalıoglu KO, Üçılık AM, Ulusoy M, Erkmen H. Yale Brown Obsesyon Kompulsiyon Derecelendirme Ölçeği'nin Geçerlik-güvenilirlik Çalısması. 29.Ulusal Psikiyatri Kongresi Program ve Bildiri Özetleri Kitabı, 1993; 86.

10. Boysan M, Beşiroğlu L, Çetinkaya N, Atlı A, Aydın A. Ob-sesif İnanışlar Ölçeği-44, Türkçe uyarlaması. Nöropsik Arşivi 2010; 47: 216-222.
OKB hastalarında kontrol ihtiyacı alt boyutunu anksiyete bozukluğu olan diğer hastalardan anlamlı yüksek olarak değerlendirmişlerdir. Ayrıca, düşünceleri kontrol ihtiyacı ile anksiyetenin ilişkili olduğunu da saptamışlardır. Yine Myers ve Wells (29), OKB hastalarında kontrol ihtiyacı ile kontrol edilmezlik tehlike alt boyutlarını anlamlı olarak bulmuşlardır.

$\mathrm{Bu}$ çalışma; çalışmanın kesitsel olması, örneklem sayısının yeterli olmaması, değerlendirmelerin hastaların kendilerinin doldurdukları ölçeklerle yapılıyor olmasının kısıtılıklarına rağmen bu alanda yapılmış ilk çalışmalardan olması açısından önemlidir. Bulgularımızın önem kazanabilmesi için daha büyük örneklem gruplarında daha ileri araştırmalara ihtiyaç duyulmaktadır.

11. Soykan C. Institutionaldifferencesandcasetypicality as relatedtodiagnosissystemseverity, prognosisandtreat- ment. Master tezi, ОDтÜ, Ankara, 1989.

12. Aslan $S$, Türkçapar $H$, Güney $E$, Eren $N$, Akkoca $Y$, Uğurlu $M$, Karakaş G. Beck Bilişsel i̇çgörü Ölçeği Türkçe Formunun Şizofrenik Hastalar için Güvenilirlik ve Geçerlik Çalışması. Klinik Psikiyatri 2005; 8: 186-19.

13. Yılmaz E, Gençöz T, Wells A. Thetemporalprecedence of metacognition in thedevelopment of anxietyanddepressionsymptoms in thecontext of life-stress: a prospectivestudy. J AnxietyDisord 2011; 25 (Suppl. 3): 389396.

14. Tosun A, Irak M. Üst-Biliş-Ölçeği Türkçe uyarlaması. Türk Psikiyatri Dergisi 2008; 19: 67-80.

15. Hermans D, Martens K, DeCort K, Pieters G, Eelen P. Realitymonitoringandmetacognitivebeliefsrelatedtocognitiveconfidence in obsessive-compulsivedisorder. BehavResTherapy 2003; 41: 383-401.

16. Buruin GO, Muris P, Rassin E. Aretherespecificmetacognitionsassociatedwithvulnerabilitytosymptoms of worryandobsessivethoughts? PersonalityandlndividualDifferences 2004; 42: 689-699.

17. Cuchii M, Vittoria B, Daniele C, Ricci L, Conca V, Ron- chi P, Smeraldi E. An exploratorystudy on metacognition in obsessive-compulsivedisorderandpanicdisorder. CompPsych 2012; 546-53.

18. Moritz S, Peters M, LarOi F, Lincoln T. Metacognitivebe- liefs in obsessive-compulsivepatients: a comparisonwithhealthyandschizophreniaparticipants. CognNeuropsychiatry 2010; 15: 531-548. 
19. Sica C, Steketee G, Ghisi M, Chiri LR, Franceschini S. Metacognitivebeliefsandstrategiespredictworry, obses- sivecompulsivesymptomsandcopingstyles: a preliminaryprospectivestudy on an Italiannonclinicalsample. ClinPsycholPsychother 2007; 14: 258-268.

20. Myers SG, Fisher PL, Wells A. An empirical test of themetacognitive model of obsessive-compulsivesymptoms: Fusionbeliefs, beliefsaboutrituals, and stop signals. J AnxietyDisord 2009; 23: 436-442.

21. Grotte T. Metacognitions, responsibility, andperfection- ism in obsessive-compulsivedisorder.NorwegianUniSc- iTechnol 2011; 39.

22. Corcoran KM, Woody SR. Appraisals of obsessional- thoughts in normal samples. BehavResTherapy 2008; 46: 71-83.

23. Nieto PA, Delgado RM, Mateos LL, Bueno N. Cognitivecontrolandanxietydisorders: metacognitivebeliefsandstrategies of controlthought in GAD and OCD. Clinand- Health 2010; 21 : 159-166.

24. Safranci B. Theassociationbetweenmetacognition- sandpsychologicalsymptoms: moderator role of copingstrategies Uzmanlık Tezi, Ankara: Ortadoğu Teknik Üniversitesi, Psikoloji Bölümü, 2010.

25. Matthews G, Hillyard EJ, Campbell SE. Metacognitionandmaladaptivecoping as components of test anxiety. ClinicalPsychologyandPsychotherapy 1999; 6: 111-125.

26. Gwilliam P, Wells A, Cartwright-Hatton S. Does metacognitionorresponsibilitypredictobsessive-compulsivesymptoms: a test of themetacognitive model. ClinPsycholPsychother 2004; 11: 137-144.

27. Barahmand $U$. Meta-cognitiveprofiles in anxietydisor- ders. PsychRes 2009; 240-243.

28. García-Montes JM, Pérez-Álvarez M, Balbuena CS, Garcelán SP andCangas AJ. Metacognitions in patientswithhallucinationsandobsessive-compulsivedisorder: thesuperstitionfactor. BehavResTher2006; 44: 10911104.

29. Myers SG, Wells A. Obsessive-compulsivesymptoms: thecontribution of metacognitionsandresponsibility. J AnxietyDisord 2005; 19: 806-817. 